\title{
Severity of depressive symptoms as a predictor of mortality: The English Longitudinal Study of Ageing
}

James White ${ }^{1}$, Paola Zaninotto ${ }^{2}$, Kate Walters ${ }^{3}$, Mika Kivimäki ${ }^{2}$, Panos Demakakos ${ }^{2}$, Aparna Shankar ${ }^{2}$, Meena Kumari ${ }^{4}$ John Gallacher ${ }^{1}$, G. David Batty ${ }^{2,5,6}$

${ }^{1}$ School of Medicine, Cardiff University, Cardiff, CF14 4YS, UK

${ }^{2}$ Department of Epidemiology and Public Health, University College London, London,

${ }^{3}$ Department of Primary Care and Population Health, University College London, London, NW3 2PF, UK

${ }^{4}$ Institute for Social and Economic Research, University of Essex, Colchester, CO4 3SQ, UK

${ }^{5}$ Centre for Cognitive Ageing and Cognitive Epidemiology, University of Edinburgh, Edinburgh, EH8 9JZ, UK

${ }^{6}$ Alzheimer Scotland Dementia Research Centre, University of Edinburgh, Edinburgh, EH8 EH8 9JZ, UK 


\begin{abstract}
Background - Major depressive disorder and sub-threshold depression have been associated with premature mortality. We investigated the association between depressive symptoms and mortality across the full continuum of severity.
\end{abstract}

Methods - We used Cox proportional hazards models to examine the association between depressive symptom severity, assessed using the eight-item Center for Epidemiological Studies Depression Scale (CES-D; range of 0 to 8), and the risk of all-cause mortality over a 9-year follow-up, in 11,104 members of The English Longitudinal Study of Ageing.

Results - During following up, one fifth of study members died $(\mathrm{N}=2,267)$. Depressive symptoms were associated with increased mortality across the full range of severity $(P$ for trend $<0.001)$. Relative to study members with no symptoms, an increased risk of mortality was found in people with depressive symptoms of a low (hazard ratio (HR) for a score of two was $1.59 ; 95 \%$ confidence interval $(\mathrm{CI})=1.40,1.82)$, moderate $($ four: $\mathrm{HR}=1.80 ; 95 \% \mathrm{CI}=$ $1.52,2.13$ ) and high severity (eight: $\mathrm{HR}=2.27 ; 95 \% \mathrm{CI}=1.69,3.04)$, suggesting risk emerges at low levels but plateaus thereafter. A third of participants $(36.4 \%$; $95 \%$ CI $35.5 \%$, 37.3\%) reported depressive symptoms associated with an increased mortality risk. Adjustment for physical activity, physical illnesses, and impairments in physical and cognitive functioning attenuated this association $(P$ for trend $=0.25)$.

Conclusions - Depressive symptoms are associated with an increased mortality risk even at low-levels of symptom severity. This association is explained by physical activity, physical illnesses, and impairments in physical and cognitive functioning. 


\section{Introduction}

Several systematic reviews have shown that a diagnosis of major depressive disorder (Cuijpers et al. 2013; Cuijpers \& Smit 2002; Saz \& Dewey 2001), minor depression (Saz \& Dewey 2001), and screening positive for 'caseness' on self-report scales of depressive symptoms (Cuijpers et al. 2013; Saz \& Dewey 2001) are associated with an elevated risk of mortality. In the few studies which have examined depressive symptoms across the full continuum of severity, an increased risk of mortality has emerged in some at moderate levels of depressive symptom severity (Almeida et al. 2010; Scafato et al. 2012; Schoevers et al. 2009), whereas in others risk is only elevated in people with more severe symptoms (Everson-Rose et al., 2004; Ryan et al. 2008; van den Brink et al. 2005; Wulsin et al. 2005). In all of these studies, scores on the severity of depressive symptoms were collapsed into a small number of categories, (Almeida et al. 2010; Everson-Rose et al. 2004; Ryan et al. 2008; Scafato et al. 2012; Schoevers et al. 2009; van den Brink et al. 2005; Wulsin et al. 2005), so limiting insights into the "shape" of the depressive symptom-mortality relation (i.e., dose-response versus threshold).

We undertook an analysis of the association between depressive symptoms and mortality across the full range of severity of depressive symptoms in the English Longitudinal Study of Ageing, a large, well-characterized, community-based cohort study of older adults. We hypothesized that the association between depressive symptoms and the risk of all-cause mortality would emerge at a severity below current thresholds for identifying clinically relevant symptoms of depression.

\section{Methods}


We used data from the English Longitudinal Study of Ageing (ELSA). Initiated in 2002/3, ELSA is an on-going, longitudinal, biannual, nationally representative, prospective cohort study of health and ageing (Mindell et al. 2012). It is derived from adults aged 50 years of age or older who had earlier participated in the Health Survey for England (HSE) in 1998, 1999, and 2001. Comparisons of the social and demographic characteristics of participants with the national census show that this sample was representative of the English population (Steptoe et al. 2013). We excluded 287 participants who did not give consent to link to the mortality records, resulting in a sample of 11,104 study members $(6,054$ women and 5,050 men). Ethical approval for the ELSA was given by the National Research Ethics Service (MREC/01/2/91).

\section{Measurement of Depressive Symptoms}

During the 2002/03 household visit, information was collected on depressive symptoms using a computer assisted personal interview. Depressive symptoms were measured using the eightitem Center for Epidemiological Studies-Depression scale (CES-D; Radloff 1977; Turvey et al. 1999). Used in the Health and Retirement Study (Steffick \& the HRS Health Working Group. 2000) and other population-based studies (Radloff 1977; Turvey et al. 1999), the CES-D captures information on depressive symptoms and somatic complaints experienced in the past week (see supplementary information for individual scale items). A dichotomous (yes/no) response to each item results in a total score of between zero (no symptoms) and eight (most severe symptoms). This short version has good internal consistency (Cronbach's $\alpha>0.95$ ) and has comparable psychometric properties to the full 20-item CES-D (Radloff 1977; Turvey et al. 1999). A total CES-D score of three or more (Turvey et al. 1999) or four or more (Steffick \& the HRS Health Working Group. 2000) has been used to denote "caseness". These thresholds have been validated against standardized psychiatric interviews 
for depression in older adults, and are equivalent to the conventional demarcation point of 16 or more on the full 20-item CES-D (Steffick \& the HRS Health Working Group. 2000; Turvey et al. 1999).

\section{Measurement of Covariates}

From the 2002/3 interview we obtained information on social, demographic, clinical, and lifestyle covariates using a computer assisted personal interview. Socioeconomic position was based on the National Statistics Socio-economic Classification (NS-SEC) classification system (Rose \& Pevalin 2003). A wealth score was based on the sum of all financial, physical (businesses, land) and housing wealth, minus debts and pension payments (Banks et al. 2006). Cohabitation status was defined as currently living alone or not. Self-reported health behaviors included smoking status (current, ex-smoker, and never), frequency of alcohol consumption in the past year (not at all, on special occasions, once or twice a month, once or twice a week, daily, $\geq 2$ times a day), and physical activity during leisure time, recorded as participation in vigorous, moderate, and mild activities (more than once per week, once per week, one to three times per month, hardly ever) (Hamer et al. 2009).

Measures of health included lifetime self-reported doctor diagnoses of chronic somatic conditions (chronic obstructive pulmonary disorder [COPD], asthma, diabetes, and arthritis), circulatory disease (hypertension, prior heart attack, stroke, angina), heart conditions (murmur, abnormal heart rhythm), depression and cancer. The use of antidepressants was recorded at wave 0 (HSE interviews in 1998, 1999 and 2001). Cognitive function was assessed using a test of memory and executive function (Steel et al. 2004). Functional impairments were assessed by asking participants whether they experienced difficulties, for at least three months, with six activities of daily living (ADL) and seven 
instrumental activities of daily living (IADL; Steel et al. 2004). Participants reporting one or more problems with an ADL or IADL were classified as having a functional impairment.

\section{Mortality ascertainment}

All-cause mortality was ascertained for a nine year period for consenting study members $(11,104 ; 97.5 \%$ of eligible participants) by linking to the UK National Health Service mortality register up to until the $15^{\text {th }}$ March 2012. In the UK, registration of death within 5 days is a legal requirement so participants not registered as dead were assumed to be alive.

\section{Statistical Analysis}

The characteristics of participants were compared according to the severity of their depressive symptoms using the chi-square test and analysis of variance. We then used Cox proportional hazards models (Cox 1972), with accompanying 95\% confidence intervals, to estimate the association between depressive symptoms and mortality. We ascertained that the proportional hazards assumption had not been violated by inspecting the $\log (-\log ($ survival $))$ plot and Schoenfeld residuals. Participants scoring 0 on the CES-D were regarded as being free of depressive symptoms and this was our reference group. We compared this reference group with those participants scoring in each of the remaining eight groups, plotted KaplanMeier survival curves for each group, and also reported HRs per standard deviation increase in depressive symptoms (standard deviation: 2.00).

Survival time was measured in months from the date of interview to date of death or the 15th March 2012 - which ever came first. Emigrants were included in analyses with the date of their last interview as their censoring date. In preliminary analyses, there was no 
evidence that the association between depressive symptoms and mortality was modified by sex, so data for men and women were pooled and analyses sex-adjusted. We also took into account potentially important covariates, grouped according to themes: basic model: age, sex and ethnicity; socioeconomic position, health behaviours, chronic conditions, circulatory disease, heart conditions, cancer, tests of cognitive function, any functional impairment, all diagnosed conditions, any antidepressant use reported in HSE interviews in 1998, 1999 and 2001, and a fully adjusted model with all variables. As depression and cognitive function share symptoms (e.g. impaired concentration, fatigue) the adjustment for cognitive function could be considered an example of over adjustment. We therefore show models with and without the addition of cognitive function. The effect on the HR of adjusting for each set of covariates was estimated using the following formula ([HR basic model-1] - [HR adjusted model-1] / [HR basic model-1]) x 100\% (Batty et al. 2006).

\section{Sensitivity Analysis}

We conducted several planned sensitivity analyses. We compared people with data missing for one or more variables with those with complete data using t-tests and the $\chi^{2}$ test. The proportion of missing data from item non-response was then imputed using multiple imputation by chained equations which included all variables (including mortality) in the prediction model using the ice command in Stata v.13 to generate 10 imputed datasets (White et al. 2011). To examine the effect of imputing data on the association between depressive symptoms and mortality we ran our analysis in a sample with no missing data $(n=10,131)$. In addition, we calculated a depressive symptom score after removing three items relating to somatic symptoms (see supplementary information for scale items), to examine if associations with mortality could be attributed to somatic complaints brought about by 
physical illness, rather than depressive symptoms. To examine reverse cause, whereby somatic illness might have increased the risk of both depressive symptoms and death, we carried out sub-group analysis after excluding the 982 deaths that occurred within the first five years of follow-up. All analyses were conducted using Stata v.13. The reporting of this study conforms to the STROBE statement (von Elm et al. 2007). 


\section{Results}

Table 1 shows the characteristics of participants according to the severity of their depressive symptoms. The majority of people reported at least one depressive symptom $(59.5 \%, 95 \%=$ 58.7-60.5) and the mean symptom severity score was $1.68(\mathrm{SD}=2.00$; range $0-8$; median $=$ 1.00; interquartile range $1.00-2.00)$. People reporting a greater severity of depressive symptoms were more likely to be female, older, non-white, employed in a routine occupation, have lower wealth, live alone, have impaired physical functioning, a smoker, hardly ever engage in physical activity, use anti-depressants, have lower memory and executive function scores, and report a doctor diagnosed health condition, than those with lower scores $(P<0.001$, table 1). There was also evidence that the highest levels of alcohol consumption were found in study members at opposing ends of the continuum of depressive symptoms.

Of the 11,104 participants in the ELSA, 2,267 (20.4\%) died during a mean follow-up of 9.1 years $(\mathrm{SD}=2.3)$. Figure 1 shows a positive trend was found with more severe depressive symptoms associated with a higher rate of mortality ( $P$ for trend $<0.001$ ). After adjustment for socioeconomic position, the strength of the association between depressive symptoms and mortality (HR per one SD disadvantage) reduced from 1.26 in the basic model (age-, sex- and ethnicity-adjusted) to 1.20, representing 23\% attenuation in risk. The greatest reduction in HRs occurred after adding health behaviors to the model (a $62 \%$ reduction compared to basic model), followed by functional impairments (54\%) and physician diagnoses $(23 \%)$, although after these separate adjustments the trend remained statistically significant the $P<0.001$ level. After full adjustment, the positive association between symptom severity and mortality was effectively eliminated (100\% attenuation, $P$ for trend= 0.25, Figure 1 and Supplementary Table S1). Of the factors entered into the multivariable model, physical activity and functional impairments alone accounted for $73 \%$ of the depressive symptom-mortality association. 
The unadjusted Kaplan Meir failure curve (Figure 2), 95\% CIs for the HRs for a CESD score of 0 to 8 (Supplementary Table S1) and survival curve (Supplementary Figure S1) suggest there is a threshold in the association between depressive symptoms and mortality. Although the HRs increase with symptom severity there is not a statistically significant increase in risk after a score of two (log rank for a score of $<2$ vs. $\geq 2=2416.87 ; P<0.001)$. Figure 2 shows that by 70 years of age $10 \%$ of people with a depressive symptom score $\geq 2$ had died, a mortality rate that is not reached until age 75 years in those with a depressive symptom score $<2$.

Sensitivity Analysis

Data were missing for one or more variables for $8.8 \%(n=973)$ of the sample. Compared to those study members who featured in the analytical sample, people with missing data were more likely to be older, female, non-white, be in the lowest quintile for wealth, live alone, have had a heart attack, stroke, have diabetes, a heart condition, be inactive at mild, moderate or vigorous intensities, have a functional impairment, but less likely to drink heavily, or have smoked. However, no more likely to have angina, cancer, arthritis, COPD, asthma, be in a lower social class, or report using antidepressants. We examined the impact on our main estimates of missing data by repeating the analysis in participants without any missing data $(n=10,131)$. The results were comparable to those in the main analysis (age, sex- and ethnicity-adjusted HR per SD disadvantage with imputed data was $1.26,95 \% \mathrm{CI}=1.22-1.31$; the $\mathrm{HR}$ in sample without any missing data was 1.25 , 95\% CI = 1.21-1.31; Supplementary Table S1 and S3). We also re-ran our analysis after removing items from the depressive symptom scale relating to somatic symptoms. The association between depressive symptoms and mortality was slightly attenuated after 
removing somatic symptoms, but the trend remained significant $(P<0.001$, Supplementary Table S4).

Sub-group analysis

We excluded 982 deaths which occurred within the first five years of follow-up to test for reverse causality. These exclusions slightly reduced the strength of the association between depressive symptoms and mortality, but replicated the trend found in the main analysis (Supplementary Table S5). 


\section{Discussion}

The main finding in this study was an association between depressive symptoms across the full range of severity and all-cause mortality. We found that even in people with low to moderate symptom scores that they would not usually bring them to the attention of mental health services, experienced an increased risk of mortality. Excluding deaths occurring in the first five years of follow-up produced only a modest attenuation of the association suggesting it may be partially attributable to reverse cause. Adjustment for a wide range of potential confounding factors, including levels of physical inactivity, cognitive function, impairments and physical illnesses fully attenuated the association.

We identified seven cohort studies that had examined the association between depressive symptoms across the continuum of severity and mortality (Almeida et al. 2010; Everson-Rose et al. 2004; Ryan et al. 2008; Scafato et al. 2012; Schoevers et al. 2009; van den Brink et al. 2005; Wulsin et al. 2005). Our results are broadly consistent with these studies, but comparisons are hampered by the wide variation in measures of depressive symptoms and the categorization of depressive symptom scores used. For example, we replicated the finding of a cohort of Australian men (Almeida et al. 2010) and the Italian Longitudinal Study of Ageing (Scafato et al. 2012) which both found the risk of mortality was raised at low levels of symptom severity on the Geriatric Depression Scale (GDS). However, as one used the 15-item (Almeida et al. 2010) and the other a 30-item version of the GDS (Scafato et al. 2012), and both collapsed symptom scores, the point at which mortality risk became elevated was unclear. Other investigators have found the risk of mortality to become raised in the highest tertile (Everson-Rose et al. 2004), or quintile (Ryan et al. 2008) of depressive symptom severity scores. Our findings do, however, replicate those of an individual-participant meta-analysis of the association between psychological distress, across the full range of symptoms severity and mortality (Russ et al. 2012). 
The mechanism underpinning the association between the depressive symptoms and mortality is not well understood. To date, the most consistent pattern of attenuation of the association between depressive symptoms and all-cause mortality has been observed for physical illness (Houle 2013; Wulsin et al. 2005), functional impairments (Everson-Rose et al. 2004; Ganguli M et al. 2002), and health behaviors (Everson-Rose et al. 2004; Penninx BH 1999; Schulz et al. 2000; Wulsin et al. 2005). We replicated these findings, with functional impairments explaining $54 \%$ and health behaviors $62 \%$ of the association between depressive symptoms and mortality. In particular, physical activity and functional impairments alone explained $73 \%$ of this association. This pattern of attenuation is either consistent with confounding or mediation. It could be that inactivity and functional impairments increase depressive symptoms and the risk of mortality, suggesting confounding. Alternatively, as engaging in low levels of physical activity has been shown to slow the progression in mobility impairments (Miller et al. 2000), these factors could form part of an indirect mechanism which explains the association between depressive symptoms and mortality (Blazer et al. 2001). A recent analysis of the Americans' Changing Lives Study provided partial support for a mediational hypothesis showing time-varying changes in physical illness and functional impairments mediated the association between baseline depressive symptoms and mortality; (Houle 2013) but changes in physical health conditions which preceded the assessment of depressive symptoms did not. Although randomized trials have shown mixed treatment effects of exercise on depression (Cooney et al. 2013), few have investigated whether treatments which are effective in reducing depressive symptoms also improve functional impairment and levels of physical activity. These studies should also assess whether these factors mediate any treatment effect on mortality.

An alternative explanation is a direct effect, where depressive symptoms cause a physiological change which increases the risk of mortality. Depressive symptoms are 
associated with elevated inflammatory markers, including levels of C-reactive protein, interleukin 6 (IL-6), and tumor necrosis factors (Dinan 2009). Injection with interferon-alpha (which increases cytokines and cortisol) (Gisslinger et al. 1993) has also been shown to elicit short-term increases in depressive symptoms (Capuron et al. 2003), and a meta-analysis of 22 trials of antidepressants approved by the United States Food and Drug Administration showed a reduction in depressive symptoms was accompanied by a decrease in inflammatory cytokines after drug therapy (Hannestad et al. 2011). However, the use of antidepressants has also been associated with elevated C-reactive protein levels (Hamer et al. 2011) and an increased risk for cardiovascular disease independent of comorbidity (Hamer et al. 2010), such that the association between depressive symptoms, antidepressants and mortality is unclear. In the present study, adjustment for antidepressant had essentially no effect on risk estimates, suggesting antidepressant use is unlikely to explain the association between mortality and depressive symptoms.

The main strength of this study is that it is with a nationally-representative sample, had a nine year follow-up, and detailed assessments of covariates. The large number of deaths $(\mathrm{n}=2,267)$ allowed reverse causality to be investigated as a sufficient number of deaths remained after those occurring in the first five years of follow-up were excluded. The study also has some weaknesses. The CES-D although widely used in population-based studies is not without limitations. The scale only assesses symptoms in the past week, and does not provide a clinical diagnosis of major depression, even though there is evidence that screening positive on the eight-item CES-D we used is associated with a diagnosis of major depressive disorder (Steffick \& the HRS Health Working Group. 2000; Turvey et al. 1999). Secondly, potentially important covariates such as adherence to psychological treatments (DiMatteo et al. 2000), diet and disease severity were not available. Whilst we did not directly measure disease severity, our measures of mobility and functional impairment are indicators of disease 
severity, as they reflect the impact of multiple co-morbidities on the individual. If these factors were associated with depressive symptoms and mortality risk in a pattern which replicated the threshold we observed, the association may be due to confounding. Third, around $11 \%$ of participants had missing data for one or more variables; sensitivity analysis comparing the hazard ratios across complete case and imputed datasets showed no difference, suggesting bias introduced by missing data was minimal. Fourthly, as depressive symptoms are typically of a lower severity in people aged fifty to sixty years old than in younger populations (Sutin et al. 2013), these finding may not generalize to people aged under the age of fifty.

In this large prospective study of men and women aged over 50 years, depressive symptoms were associated with an increased risk of mortality, even at low-levels of symptom severity. Levels of physical inactivity, cognitive function, functional impairments and physical illnesses fully attenuated this association. A third of older adults had symptoms at a severity associated with an increased risk for mortality, and one in ten scored under validated cut-points for clinically significant depressive symptoms but experienced an increased risk for all-cause mortality, suggesting current cut-points do not identify one in ten people at an increased risk for early death. 


\section{Supplementary material}

For supplementary material accompanying this paper visit http://journals.cambridge.org/action/displayJournal?jid=PSM

\section{Acknowledgements}

The English Longitudinal Study of Ageing was developed by a team of researchers based at the University College London, National Centre for Social Research, and the Institute for Fiscal Studies. The data were collected by the National Centre for Social Research. The funding is provided by the National Institute of Aging in the United States, and a consortium of UK government departments coordinated by the Office for National Statistics. The developers and funders of the English Longitudinal Study of Ageing and the UK Data Archive do not bear any responsibility for the analyses or interpretations presented here. JW is supported by the support of The Centre for the Development and Evaluation of Complex Interventions for Public Health Improvement (DECIPHer), a UKCRC Public Health Research Centre of Excellence. Joint funding (MR/KO232331/1) from the British Heart Foundation, Cancer Research UK, Economic and Social Research Council, Medical Research Council, the Welsh Government and the Wellcome Trust, under the auspices of the UK Clinical Research Collaboration, is gratefully acknowledged. MK is supported by the UK Medical Research Council (K013351), the Academy of Finland, the United States National Institutes of Health (R01HL036310; R01AG034454) and by a professorial fellowship from the Economic and Social Research Council. GDB is a member of the University of Edinburgh Centre for Cognitive Ageing and Cognitive Epidemiology, part of the cross council Lifelong Health and Wellbeing Initiative (G0700704/84698). 
Declaration of interest

None. 


\section{References}

Almeida OP, Alfonso H, Hankey GJ, \& Flicker L (2010). Depression, Antidepressant Use and Mortality in Later Life: The Health in Men Study, PLoS ONE 5, e11266.

Banks J, Breeze E, Lessof C, \& Nazroo J (2006). Retirement, health and relationships of the older population in England: The 2004 English Longitudinal Study of Ageing (Wave 2)

Batty GD, Der G, Macintyre S, \& Deary IJ (2006). Does IQ explain socioeconomic inequalities in health? Evidence from a population based cohort study in the west of Scotland, BMJ 332, 580-584.

Blazer DG, Hybels CF, \& Pieper CF (2001). The association of depression and mortality in elderly persons: a case for multiple, independent pathways, The journals of gerontology. Series A, Biological sciences and medical sciences 56, M505-509.

Van den Brink CL, Tijhuis M, van den Bos GAM, Giampaoli S, Nissinen A, \& Kromhout D (2005). The contribution of self-rated health and depressive symptoms to disability severity as a predictor of 10-year mortality in European elderly men, American journal of public health 95, 2029-2034.

Capuron L, Raison CL, Musselman DL, Lawson DH, Nemeroff CB, \& Miller AH (2003). Association of exaggerated HPA axis response to the initial injection of interferonalpha with development of depression during interferon-alpha therapy, The American journal of psychiatry 160, 1342-1345.

Cooney GM, Dwan K, Greig CA, Lawlor DA, Rimer J, Waugh FR, McMurdo M, \& Mead GE (2013). Exercise for depression, The Cochrane Database of Systematic Reviews $\mathbf{9}$, CD004366.

Cox DR (1972). Regression models and life-tables, Journal of the Royal Statistical Society. Series B (Methodological), 187-220.

Cuijpers P, \& Smit F (2002). Excess mortality in depression: a meta-analysis of community studies, Journal of Affective Disorders 72, 227-236.

Cuijpers P, Vogelzangs N, Twisk J, Kleiboer A, Li J, \& Penninx BW (2013). Differential mortality rates in major and subthreshold depression: meta-analysis of studies that measured both, The British Journal of Psychiatry 202, 22-27.

DiMatteo MR, Lepper HS, \& Croghan TW (2000). Depression is a risk factor for noncompliance with medical treatment: Meta-analysis of the effects of anxiety and depression on patient adherence, Archives of internal medicine 160, 2101-2107.

Dinan TG (2009). Inflammatory markers in depression, Current Opinion in Psychiatry 22, $32-36$.

Von Elm E, Altman DG, Egger M, Pocock SJ, Gøtzsche PC, \& Vandenbroucke JP (2007). Strengthening the Reporting of Observational Studies in Epidemiology (STROBE) statement: guidelines for reporting observational studies, BMJ (Clinical research ed.) 335, 806-808. 
Everson-Rose SA, House JS, \& Mero RP (2004). Depressive symptoms and mortality risk in a national sample: confounding effects of health status, Psychosomatic medicine 66, 823830.

Ganguli M, Dodge HH, \& Mulsant BH (2002). Rates and predictors of mortality in an aging, rural, community-based cohort: The role of depression, Archives of General Psychiatry 59, 1046-1052.

Gisslinger H, Svoboda T, Clodi M, Gilly B, Ludwig H, Havelec L, \& Luger A (1993). Interferon-alpha stimulates the hypothalamic-pituitary-adrenal axis in vivo and in vitro, Neuroendocrinology 57, 489-495.

Hamer M, Batty GD, Marmot MG, Singh-Manoux A, \& Kivimaki M (2011). Antidepressant medication use and C-reactive protein: Results from two population-based studies, Brain, behavior, and immunity 25, 168-173.

Hamer M, Batty GD, Seldenrijk A, \& Kivimaki M (2010). Antidepressant medication use and future risk of cardiovascular disease: the Scottish Health Survey, European Heart Journal, ehq438.

Hamer M, Molloy GJ, de Oliveira C, \& Demakakos P (2009). Leisure time physical activity, risk of depressive symptoms, and inflammatory mediators: The English Longitudinal Study of Ageing, Psychoneuroendocrinology 34, 1050-1055.

Hannestad J, DellaGioia N, \& Bloch M (2011). The effect of antidepressant medication treatment on serum levels of inflammatory cytokines: a meta-analysis, Neuropsychopharmacology: official publication of the American College of Neuropsychopharmacology 36, 2452-2459.

Houle JN (2013). Depressive symptoms and all-cause mortality in a nationally representative longitudinal study with time-varying covariates, Psychosomatic medicine 75, 297-304.

Miller ME, Rejeski WJ, Reboussin BA, Ten Have TR, \& Ettinger WH (2000). Physical activity, functional limitations, and disability in older adults., Journal of the American Geriatrics Society; Journal of the American Geriatrics Society 48, 1264-1272.

Mindell J, Biddulph JP, Hirani V, Stamatakis E, Craig R, Nunn S, \& Shelton N (2012). Cohort Profile: The Health Survey for England, International Journal of Epidemiology 41, $1585-1593$.

Penninx BH GS (1999). Minor and major depression and the risk of death in older persons, Archives of General Psychiatry 56, 889-895.

Radloff LS (1977). The CES-D scale A self-report depression scale for research in the general population, Applied psychological measurement 1, 385-401.

Rose D, \& Pevalin DJ (2003). The NS-SEC explained, A researcher's guide to the national statistics socio-economic classification. London: Sage, 28-44.

Russ TC, Stamatakis E, Hamer M, Starr JM, Kivimaki M, \& Batty GD (2012). Association between psychological distress and mortality: individual participant pooled analysis of 10 prospective cohort studies, BMJ 345, e4933-e4933. 
Ryan J, Carriere I, Ritchie K, Stewart R, Toulemonde G, Dartigues J-F, Tzourio C, \& Ancelin M-L (2008). Late-life depression and mortality: influence of gender and antidepressant use, The British Journal of Psychiatry 192, 12-18.

Saz P, \& Dewey ME (2001). Depression, depressive symptoms and mortality in persons aged 65 and over living in the community: a systematic review of the literature, International Journal of Geriatric Psychiatry 16, 622-630.

Scafato E, Galluzzo L, Ghirini S, Gandin C, Rossi A, Solfrizzi V, Panza F, Di Carlo A, Maggi S, \& Farchi G (2012). Changes in severity of depressive symptoms and mortality: the Italian Longitudinal Study on Aging, Psychological Medicine 42, 2619-2629.

Schoevers RA, Geerlings MI, Deeg DJH, Holwerda TJ, Jonker C, \& Beekman ATF (2009). Depression and excess mortality: evidence for a dose response relation in community living elderly, International journal of geriatric psychiatry 24, 169-176.

Schulz R, Beach SR, Ives DG, Martire LM, Ariyo AA, \& Kop WJ (2000). Association between depression and mortality in older adults: the Cardiovascular Health Study, Archives of internal medicine 160, 1761-1768.

Steel N, Huppert FA, McWilliams B, \& Melzer D (2004). 7. Physical and cognitive function

Steffick DE, \& the HRS Health Working Group. (2000). Documentation of Affective Functioning Measures in the Health and Retirement Study, no. HRS/AHEAD Documentation Report DR-005

Steptoe A, Breeze E, Banks J, \& Nazroo J (2013). Cohort Profile: The English Longitudinal Study of Ageing, International Journal of Epidemiology 42, 1640-1648.

Sutin AR, Terracciano A, Milaneschi Y, An Y, Ferrucci L, \& Zonderman AB (2013). The trajectory of depressive symptoms across the adult life span, JAMA psychiatry 70, 803811.

Turvey CL, Wallace RB, \& Herzog R (1999). A Revised CES-D Measure of Depressive Symptoms and a DSM-Based Measure of Major Depressive Episodes in the Elderly, International Psychogeriatrics 11, 139-148.

White IR, Royston P, \& Wood AM (2011). Multiple imputation using chained equations: Issues and guidance for practice, Statistics in Medicine 30, 377-399.

Wulsin LR, Evans JC, Vasan RS, Murabito JM, Kelly-Hayes M, \& Benjamin EJ (2005). Depressive Symptoms, Coronary Heart Disease, and Overall Mortality in the Framingham Heart Study, Psychosomatic Medicine 67, 697-702. 
Table 1. Characteristics of 11,104 ELSA participants according to the severity of depressive symptoms

\begin{tabular}{|c|c|c|c|c|c|c|c|c|c|c|}
\hline & \multicolumn{9}{|c|}{ Depressive symptoms } & \multirow[b]{2}{*}{$\begin{array}{l}\text { P-value } \\
\text { for trend }\end{array}$} \\
\hline & $\begin{array}{c}0 \\
\text { (None) }\end{array}$ & 1 & 2 & 3 & 4 & 5 & 6 & 7 & $\begin{array}{c}8 \\
\text { (highest) }\end{array}$ & \\
\hline No. of participants & $40.4(4488)$ & $23.2(2578)$ & $11.6(1287)$ & $8.1(897)$ & $5.6(620)$ & $4.2(463)$ & $3.1(349)$ & $2.2(248)$ & $1.6(174)$ & \\
\hline No. of deaths & $15.1(679)$ & $17.6(453)$ & $26.9(346)$ & $28.7(258)$ & $28.5(177)$ & $29.6(137)$ & $29.2(102)$ & $26.2(65)$ & $28.7(50)$ & $<0.001$ \\
\hline Age (Years), Mean (SD) & $63.0(9.36)$ & $64.0(9.9)$ & $65.7(10.7)$ & $65.6(10.6)$ & $65.7(10.1)$ & $65.2(10.5)$ & $65.3(10.9)$ & $64.1(10.9)$ & $63.2(109)$ & $<0.001$ \\
\hline Female & $47.0(2113)$ & $57.1(1472)$ & $57.8(744)$ & $58.0(521)$ & $64.8(402)$ & $63.7(295)$ & $64.0(223)$ & $70.5(174)$ & $63.3(110)$ & $<0.001$ \\
\hline Non-white ethnic group & $1.8(81)$ & $2.4(62)$ & $2.8(36)$ & $3.2(29)$ & $3.5(22)$ & $6.0(28)$ & $4.3(15)$ & $5.6(14)$ & $7.5(13)$ & $<0.001$ \\
\hline Routine occupation a & $39.8(1786)$ & $44.0(1135)$ & $51.9(669)$ & $53.3(478)$ & $56.7(351)$ & $59.3(275)$ & $59.4(208)$ & $69.1(169)$ & $68.6(119)$ & $<0.001$ \\
\hline Living alone & $22.0(989)$ & $29.3(754)$ & $38.5(495)$ & $37.4(336)$ & $41.1(255)$ & $48.1(223)$ & $51.7(181)$ & $53.8(133)$ & $69.4(121)$ & $<0.001$ \\
\hline Current smoker & $15.1(677)$ & $15.8(407)$ & $18.5(238)$ & $20.7(186)$ & $22.4(139)$ & $24.4(113)$ & $26.9(94)$ & $31.6(78)$ & $28.2(49)$ & $<0.001$ \\
\hline$\geq 2$ alcoholic drinks a day ${ }^{c}$ & $4.7(201)$ & $5.1(124)$ & $4.6(57)$ & $5.4(46)$ & $2.8(17)$ & $2.4(11)$ & $2.6(9)$ & $4.6(11)$ & $4.2(7)$ & 0.03 \\
\hline \multicolumn{11}{|l|}{ Hardly ever physically active ${ }^{d}$} \\
\hline At a mild intensity & $7.3(328)$ & $8.9(231)$ & $15.7(202)$ & $19.1(171)$ & $17.8(111)$ & $24.3(113)$ & $22.5(78)$ & $22.3(55)$ & $31.6(55)$ & $<0.001$ \\
\hline At a moderate intensity & $10.2(457)$ & $16.9(438)$ & $26.8(345)$ & $34.4(309)$ & $33.3(207)$ & $40.7(188)$ & $42.1(147)$ & $43.9(109)$ & $41.4(72)$ & $<0.001$ \\
\hline At a vigorous intensity & $53.8(2417)$ & $61.1(1583)$ & $70.8(911)$ & $72.1(647)$ & $76.8(476)$ & $79.5(368)$ & $79.4(277)$ & $81.5(202)$ & $83.9(146)$ & $<0.001$ \\
\hline Difficulty in any ADL & $8.5(383)$ & $16.8(433)$ & $28.1(362)$ & $37.2(334)$ & $38.0(235)$ & $42.9(199)$ & $44.2(155)$ & $44.9(111)$ & $52.8(92)$ & $<0.001$ \\
\hline \multicolumn{11}{|l|}{ Diagnoses and health conditions } \\
\hline Hypertension & $33.9(1523)$ & $38.3(988)$ & $39.6(509)$ & $42.9(385)$ & $45.0(279)$ & $43.3(201)$ & $42.9(150)$ & $44.6(110)$ & $42.7(74)$ & $<0.001$ \\
\hline Angina & $6.1(276)$ & $9.1(236)$ & $12.8(165)$ & $13.0(116)$ & $16.5(103)$ & $14.7(68)$ & $16.0(56)$ & $19.1(47)$ & $19.7(34)$ & $<0.001$ \\
\hline Heart attack & $4.2(190)$ & $5.8(151)$ & $6.4(82)$ & $8.0(72)$ & $9.2(57)$ & $7.8(36)$ & $9.9(35)$ & $10.1(25)$ & $9.2(16)$ & $<0.001$ \\
\hline Congenital heart condition & $8.3(371)$ & $11.3(291)$ & $12.6(162)$ & $15.1(135)$ & $13.6(84)$ & $13.6(63)$ & $12.9(45)$ & $10.5(26)$ & $14.9(26)$ & $<0.001$ \\
\hline Stroke & $2.2(101)$ & $3.8(100)$ & $6.0(77)$ & $6.4(58)$ & $7.0(44)$ & $7.2(33)$ & $7.6(27)$ & $7.5(19)$ & $7.7(13)$ & $<0.001$ \\
\hline Diabetes (type 1 and 2) & $5.8(259)$ & $6.5(167)$ & $8.0(103)$ & $10.0(89)$ & $10.6(66)$ & $13.8(64)$ & $8.6(30)$ & $8.7(22)$ & $10.3(18)$ & $<0.001$ \\
\hline COPD & $3.5(155)$ & $6.1(156)$ & $8.3(107)$ & $10.5(95)$ & $10.9(67)$ & $10.9(51)$ & $11.2(39)$ & $13.9(35)$ & $15.5(27)$ & $<0.001$ \\
\hline Asthma & $9.4(422)$ & $9.7(251)$ & $12.3(160)$ & $15.5(139)$ & $16.3(101)$ & $16.8(78)$ & $18.2(64)$ & $16.1(39)$ & $23.0(40)$ & $<0.001$ \\
\hline Arthritis & $21.9(983)$ & $32.9(850)$ & $39.1(504)$ & $42.4(381)$ & $46.5(289)$ & $51.0(236)$ & $52.9(185)$ & $45.4(113)$ & $51.7(90)$ & $<0.001$ \\
\hline Cancer & $5.4(242)$ & $6.3(161)$ & $5.8(74)$ & $7.7(69)$ & $7.3(45)$ & $8.1(37)$ & $6.9(24)$ & $6.7(17)$ & $9.2(16)$ & $<0.001$ \\
\hline Depression & $2.8(125)$ & $3.6(92)$ & $5.1(65)$ & $8.0(72)$ & $9.2(57)$ & $9.9(46)$ & $16.6(58)$ & $20.1(51)$ & $24.1(42)$ & $<0.001$ \\
\hline
\end{tabular}




\begin{tabular}{|c|c|c|c|c|c|c|c|c|c|c|}
\hline Antidepressant use ${ }^{\mathrm{e}}$ & $2.0(88)$ & $3.9(102)$ & $6.0(77)$ & $7.1(64)$ & $8.4(52)$ & $8.9(41)$ & $12.1(42)$ & $15.5(38)$ & $14.4(25)$ & $<0.001$ \\
\hline Memory index, M(SD) & $17.22(4.93)$ & $16.56(4.96)$ & $15.37(5.23)$ & $15.15(5.36)$ & $14.94(5.41)$ & $14.58(4.29)$ & $14.13(5.19)$ & $14.30(5.38)$ & $13.69(5.42)$ & $<0.001$ \\
\hline Executive function score & $18.05(4.11)$ & $17.66(4.18)$ & 16.43 & 16.32 & 15.84 & 15.66 & 15.01 & 15.12 & 14.91 & $<0.001$ \\
\hline
\end{tabular}

Data are $\%(\mathrm{~N})$ of participants unless stated otherwise.

${ }^{a}$ National Statistics Socio-economic Classification (NS-SEC) classification system: Higher managerial, administrative and professional occupations, Intermediate occupations, Routine and manual occupations; ${ }^{b}$ Total wealth excludes debt and regular pension payments; ${ }^{\mathrm{c}} \geq 2$ alcoholic drinks a day over the past year; ${ }^{\mathrm{d}}$ Hardly ever engaged in: mild; moderate; or vigorous physical activity; ${ }^{\mathrm{e}}$ Self-reported use of antidepressants in wave 0 comprising of: SSRI = Selective Serotonin Reuptake Inhibitors (British National Formulary [BNF] code: 40303) and Tricyclic antidepressants (BNF: 40301). A higher CES-D score indicates greater depressive symptoms.

$\mathrm{SD}=$ Standard deviation; COPD: Chronic Obstructive Pulmonary Disorder. 


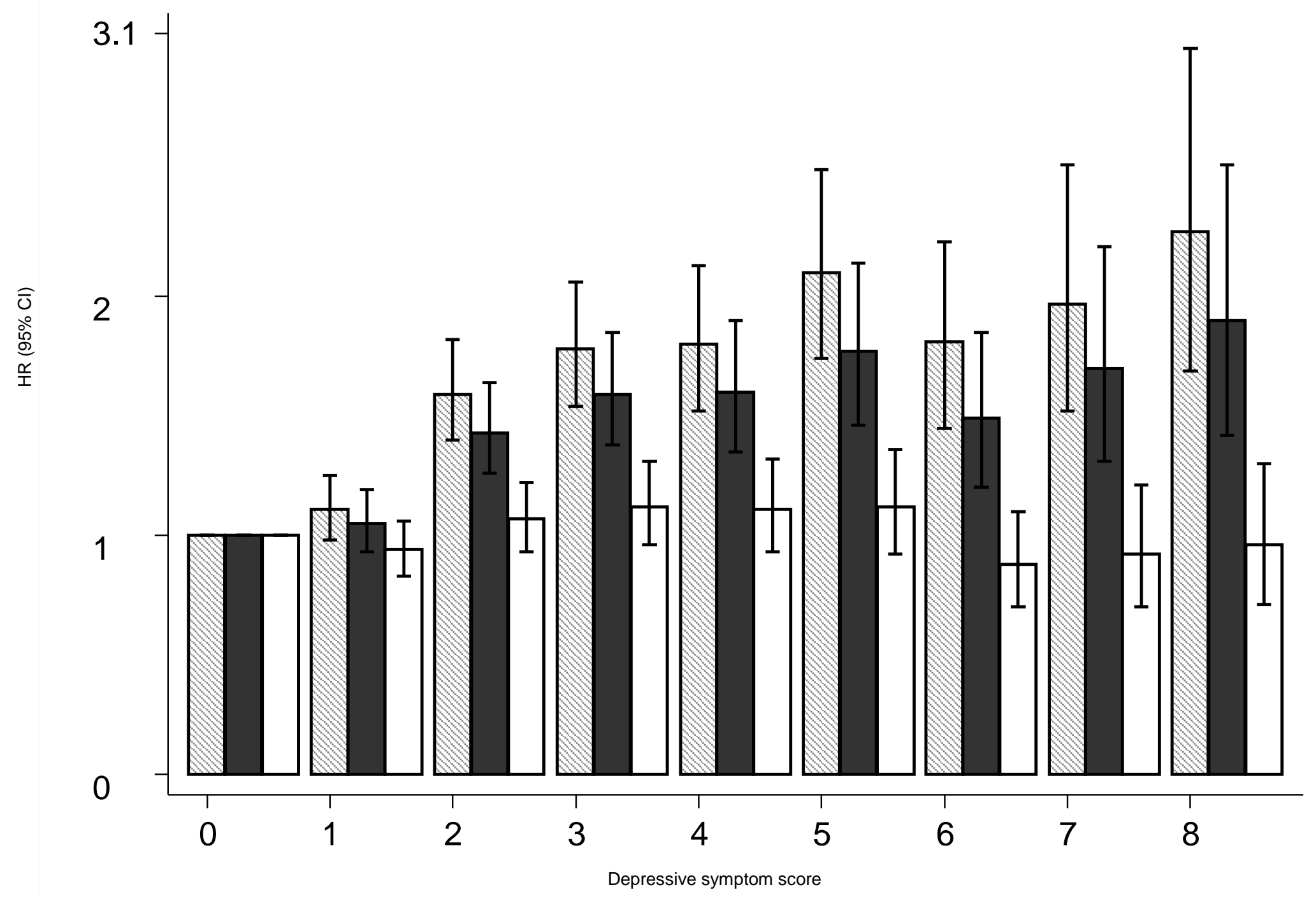

Figure 1. Basic adjustment: age, sex and ethnicity (hatched bars); basic adjustment plus any condition or diagnosis: chronic diseases, circulatory disease, and cancers (black); full adjustment: basic adjustment plus socioeconomic position, living alone, any condition or diagnosis anti- 
depressant medication, and health behaviors (white). The reference group are participants with a score of zero; a higher score indicates more severe depressive symptoms. 


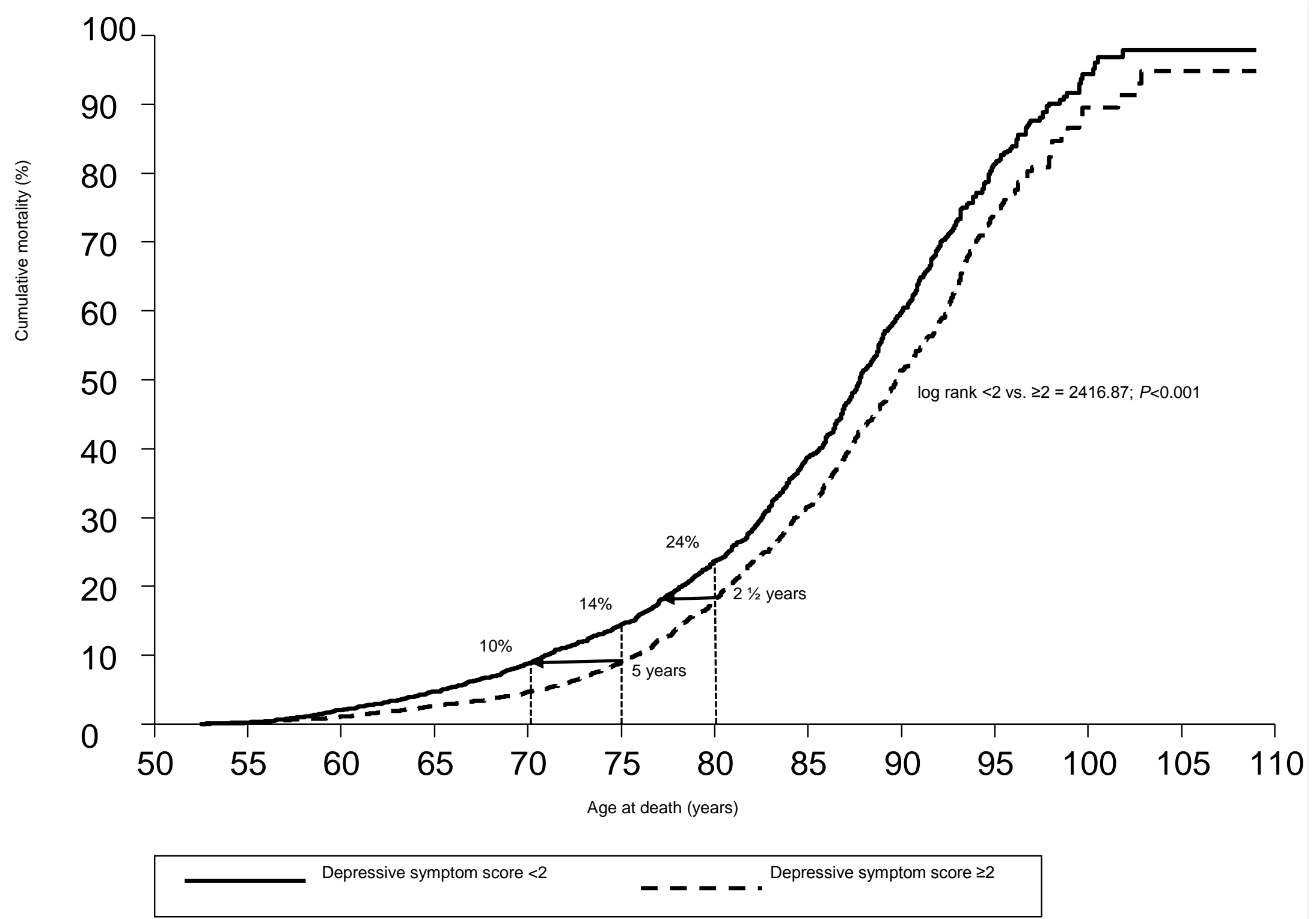

Figure 2. Kaplan-Meier failure curve for all-cause mortality in people with a depressive symptom score of $<2$ or $\geq 2$. 


\section{Supplementary tables}

1. Table S1. Hazard ratios (95\% confidence intervals) for all-cause mortality according to depressive symptoms in 11,104 men and women

2. Table S2. Hazard ratios (95\% confidence intervals) for all-cause mortality in fully adjusted model according to depressive symptoms in 11,104 men and women

3. Table S3. Hazard ratios (95\% confidence intervals) for all-cause mortality according to depressive symptoms in 10,131 participants with complete data

4. Table S4. Hazard ratios (95\% confidence intervals) for all-cause mortality according to depressive symptoms after excluding somatic symptoms from score $(\mathrm{n}=11,104)$

5. Table S5. Hazard ratios (95\% confidence intervals) for all-cause mortality according to depressive symptoms excluding deaths in first 5 years after wave one $(n=10,122)$

6. Figure S1. Kaplan-Meier survival curve for all-cause mortality according to severity of depressive symptoms (higher CES-D score indicates greater depressive symptoms).

7. Items of the 8-item version of the Center of Epidemiological Studies-Depression Scale. 
Table 1. Hazard ratios (95\% confidence intervals) for all-cause mortality according to depressive symptoms in 11,104 men and women

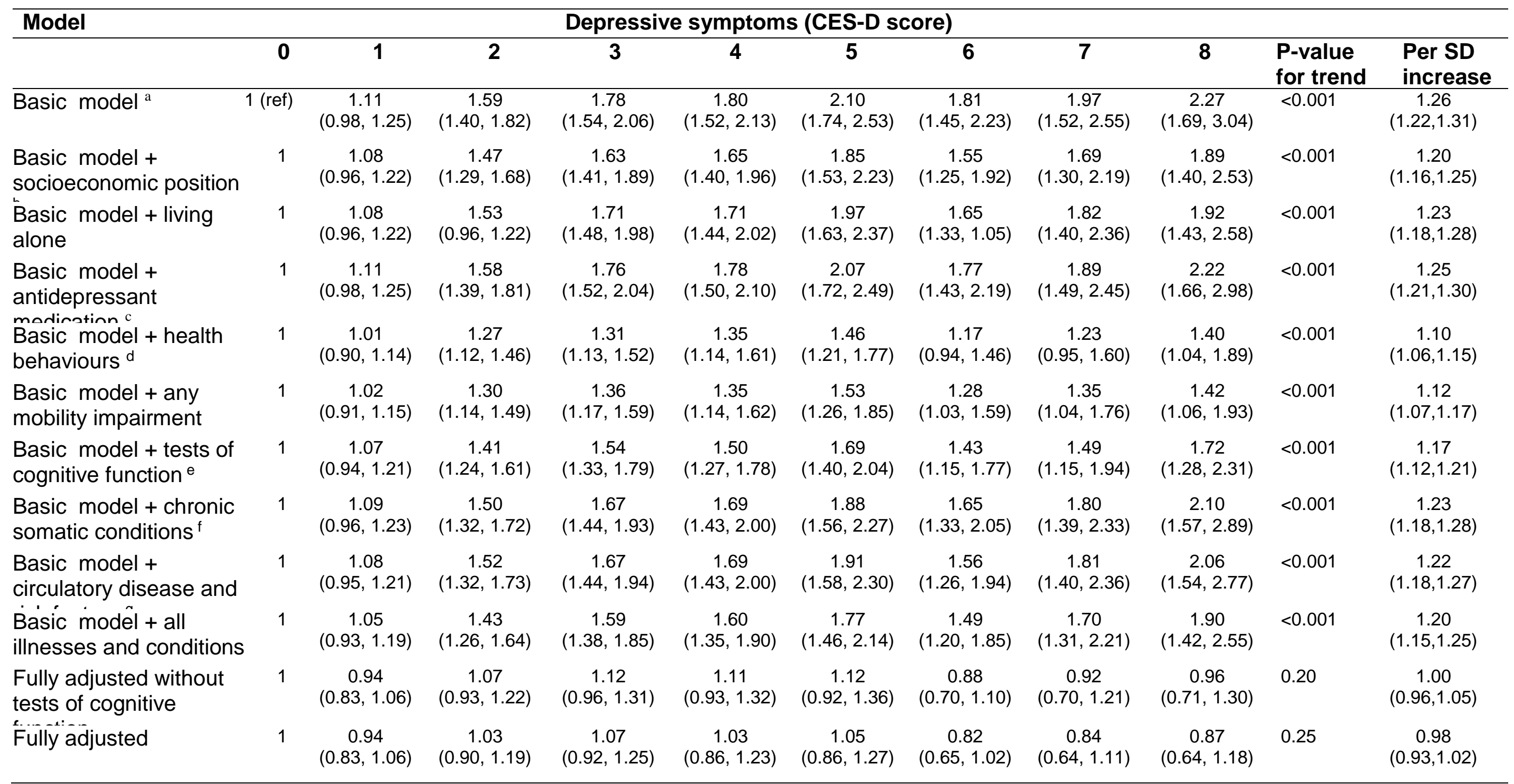


${ }^{a}$ Basic model is adjusted for age, sex and ethnicity; ${ }^{\mathrm{b}}$ Socioeconomic position comprises occupational social class according to the National Statistics Socio-economic Classification (NS-SEC) and total wealth (excluding debt and regular pension payments); ${ }^{\mathrm{c}}$ Self-reported use of antidepressants in wave 0 comprising of: SSRI = Selective Serotonin Reuptake Inhibitors (BNF: 40303) and Tricyclic antidepressants (BNF: 40301); ${ }^{\mathrm{d}}$ Health behaviours comprise smoking status, alcohol intake (per year) and physical activity; ${ }^{\mathrm{e}}$ Tests of cognitive function were on: memory and executive function; ${ }^{\mathrm{f}}$ Chronic conditions were COPD and other chronic respiratory conditions, asthma, diabetes (types 1 and 2 ) and arthritis; ${ }^{\mathrm{g}}$ Circulatory disease and risk factors comprise of hypertension, previous heart attack, stroke, angina, and congenital heart conditions. 
Table 2. Hazard ratios (95\% confidence intervals) for all-cause mortality according to depressive symptoms and fully adjusted $(\mathrm{n}=11,104)$

\begin{tabular}{|c|c|c|}
\hline Factor & Adjusted hazard ratio & $P$ value \\
\hline \multicolumn{3}{|c|}{ Depressive symptom (CES-D) score } \\
\hline 0 (lowest) & 1 (reference) & \\
\hline 1 & $0.94(0.83,1.06)$ & 0.31 \\
\hline 2 & $1.03(0.90,1.19)$ & 0.62 \\
\hline 3 & $1.07(0.92,1.25)$ & 0.37 \\
\hline 4 & $1.03(0.86,1.23)$ & 0.73 \\
\hline 5 & $1.05(0.86,1.28)$ & 0.65 \\
\hline 6 & $0.82(0.65,1.02)$ & 0.08 \\
\hline 7 & $0.84(0.64,1.11)$ & 0.22 \\
\hline \multirow[t]{2}{*}{8 (highest) } & $0.87(0.64,1.18)$ & 0.36 \\
\hline & & 0.25 (trend) \\
\hline Sex (male) & $0.59(0.53,0.64)$ & $<0.001$ \\
\hline Age, years ${ }^{a}$ & $1.06(1.06,1.07)$ & $<0.001$ \\
\hline \multicolumn{3}{|l|}{ Ethnic group } \\
\hline Non-white & 1 (reference) & \\
\hline White & $0.59(0.53,0.64)$ & $<0.001$ \\
\hline \multicolumn{3}{|l|}{ NSSEC social class } \\
\hline Routine and manual & 1 (reference) & \\
\hline Intermediate & $0.98(0.86,1.11)$ & 0.72 \\
\hline Higher managerial & $0.87(0.77,0.97)$ & 0.02 \\
\hline \multicolumn{3}{|l|}{ Quintiles of total wealth } \\
\hline 1 (lowest) & 1 (reference) & \\
\hline 2 & $1.00(0.89,1.13)$ & 0.97 \\
\hline 3 & $0.97(0.85,1.10)$ & 0.61 \\
\hline 4 & $0.90(0.78,1.04)$ & 0.17 \\
\hline \multirow[t]{2}{*}{5 (highest) } & $0.87(0.74,1.01)$ & 0.07 \\
\hline & & 0.31 (trend) \\
\hline Living alone & $1.33(1.21,1.46)$ & $<0.001$ \\
\hline \multicolumn{3}{|l|}{ Smoking status } \\
\hline Never & 1 (reference) & \\
\hline Ex-smoker & $1.24(1.12,1.38)$ & $<0.001$ \\
\hline Current smoker & $1.55(1.36,1.77)$ & $<0.001$ \\
\hline \multicolumn{3}{|c|}{ Frequency of drinking alcohol in past } \\
\hline Twice a day or more & 1 (reference) & \\
\hline Daily or almost daily & $0.91(0.75,1.12)$ & 0.38 \\
\hline Once or twice a week & $0.78(0.64,0.95)$ & 0.01 \\
\hline Once or twice a month & $0.68(0.54,0.86)$ & 0.001 \\
\hline Special occasions only & $0.90(0.73,1.10)$ & 0.29 \\
\hline Never consume & $0.95(0.77,1.17)$ & 0.64 \\
\hline
\end{tabular}


Mild intensity physical activity

More than once a week

Once a week

1 (reference)

One to three times a week

$0.98(0.77,1.24)$

0.85

$1.06(0.84,1.33)$

0.63

Hardly ever, never

$1.39(1.18,1.63)$

$<0.001$

$<0.001$

Moderate intensity physical activity

More than once a week

Once a week

1 (reference)

One to three times a week

$1.07(0.93,1.22)$

0.35

$1.10(0.92,1.32)$

0.28

Hardly ever, never

$1.42(1.25,1.60)$

$<0.001$

$<0.001$

Vigorous intensity physical activity

More than once a week

Once a week

1 (reference)

One to three times a week

$1.03(0.90,1.17)$

0.67

$1.15(0.94,1.40)$

0.17

Hardly ever, never

$1.06(0.93,1.19)$

0.14

Memory index a

$0.95(0.94,0.96)$

0.74 (trend)

Executive function score ${ }^{a}$

$0.96(0.94,0.97)$

$<0.001$

$<0.001$

Chronic conditions

COPD

Asthma

Arthritis

Diabetes (type 1 and 2)

Cardiovascular disease

Hypertension

Previous heart attack

Stroke

Angina

Congenital heart disease

Cancer

Mobility impairments

Any difficulty in a ADL

Any difficulty in a IADL

Antidepressant use
$1.53(1.35,1.75)$

$0.92(0.81,1.05)$

$0.94(0.85,1.03)$

$1.21(1.06,1.38)$

$1.05(0.96,1.16)$

$1.04(0.90,1.21)$

$1.11(0.96,1.28)$

$1.06(0.94,1.20)$

$1.40(1.25,1.56)$

$1.95(1.71,2.23)$

$1.13(1.01,1.26)$

$1.32(1.18,1.47)$

$0.99(0.82,1.19)$
$<0.001$

0.23

0.15

0.005

0.21

0.56

0.17

0.33

$<0.001$

$<0.001$

0.03

$<0.001$

0.88

${ }^{a}$ Modelled as a continuous term.

Abbreviations: NS-SEC: National Statistics Socio-economic Classification; COPD: Chronic obstructive pulmonary disorder; ADL: Activities of daily living; IADL: Instrumental activities of daily living 
Table 3. Hazard ratios (95\% confidence intervals) for all-cause mortality according to depressive symptoms in 10,131 participants with complete data

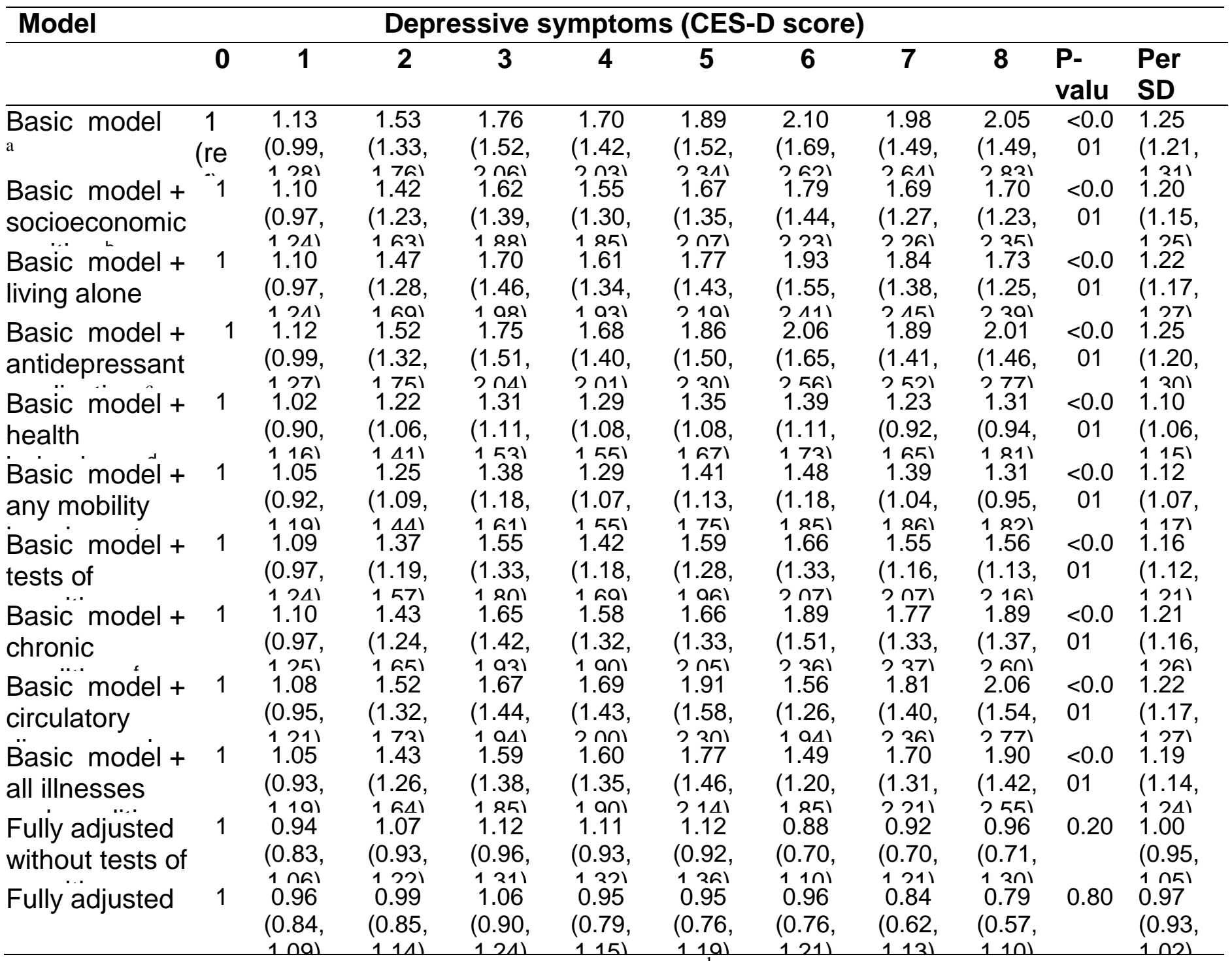

${ }^{a}$ Basic model is adjusted for age, sex and ethnicity; ${ }^{b}$ Socioeconomic position comprises occupational social class according to the National Statistics Socio-economic Classification (NS-SEC) and total wealth (excluding debt and regular pension payments); ${ }^{\mathrm{c}}$ Self-reported use of antidepressants in wave 0 comprising of: SSRI = Selective Serotonin Reuptake Inhibitors (BNF: 40303) and Tricyclic antidepressants (BNF: 40301); ${ }^{\mathrm{d}}$ Health behaviours comprise smoking status, alcohol intake (per year) and physical activity; ${ }^{\mathrm{e}}$ Tests of cognitive function were on: memory and executive function; ${ }^{\mathrm{f}}$ Chronic conditions were COPD and other chronic respiratory conditions, asthma, diabetes (types 1 and 2) and arthritis; ${ }^{\mathrm{g}}$ Circulatory disease and risk factors comprise of hypertension, previous heart attack, stroke, angina, and congenital heart conditions. 
Table 4. Hazard ratios (95\% confidence intervals) for all-cause mortality according to depressive symptoms after excluding somatic symptoms from score $(n=11,104)$

\begin{tabular}{|c|c|c|c|c|c|c|c|c|}
\hline Model & & pres & re sy & toms ( & ES-D : & ore) & & \\
\hline & 0 & 1 & 2 & 3 & 4 & 5 & $\begin{array}{l}\text { P- } \\
\text { valu }\end{array}$ & $\begin{array}{l}\text { Per } \\
\text { SD }\end{array}$ \\
\hline Basic model ${ }^{a}$ & $\begin{array}{l}1 \\
(r\end{array}$ & $\begin{array}{r}1.31 \\
(1.17\end{array}$ & $\begin{array}{r}1.45 \\
(1.26\end{array}$ & $\begin{array}{c}1.66 \\
(1.41,\end{array}$ & $\begin{array}{r}1.59 \\
(1.30\end{array}$ & $\begin{array}{r}1.84 \\
(1.47\end{array}$ & $\begin{array}{l}<0.00 \\
1\end{array}$ & $\begin{array}{l}1.15 \\
(1.11,\end{array}$ \\
\hline Basic model + & 1 & 112 & $\begin{array}{l}1 \text { a al } \\
135\end{array}$ & $\begin{array}{l}1 \text { afi } \\
1.43\end{array}$ & $\begin{array}{l}1 \text { acl } \\
1.40\end{array}$ & $\begin{array}{l}2.2 n 1 \\
1.57\end{array}$ & -000 & $\begin{array}{l}1181 \\
110\end{array}$ \\
\hline socioeconomic & & $(1.08$, & $(1.17$ & $(1.21$ & $(1.15$ & $(1.26$ & 1 & $(1.07$ \\
\hline $\begin{array}{l}\text { Basic model + } \\
\text { living alone }\end{array}$ & 1 & $\begin{array}{l}1.26) \\
1.23 \\
(1.10,\end{array}$ & $\begin{array}{l}1.35) \\
1.37 \\
(1.19\end{array}$ & $\begin{array}{l}1.50) \\
1.50 \\
(1.26 \\
1.77)\end{array}$ & $\begin{array}{l}1.47 \\
(1.20\end{array}$ & $\begin{array}{l}1.58 \\
1.58 \\
(1.26\end{array}$ & $\begin{array}{l}<0.00 \\
1\end{array}$ & $\begin{array}{l}1.14) \\
1.11 \\
(1.08\end{array}$ \\
\hline $\begin{array}{l}\text { Basic model + } \\
\text { antidepressant }\end{array}$ & 1 & $\begin{array}{l}1.30 \\
(1.16\end{array}$ & $\begin{array}{l}1.43 \\
(1.24\end{array}$ & $\begin{array}{l}1.63 \\
(1.38\end{array}$ & $\begin{array}{l}1.53 \\
(1.24 \\
1.88)\end{array}$ & $\begin{array}{l}1.80 \\
(1.44\end{array}$ & $\begin{array}{l}<0.00 \\
1\end{array}$ & $\begin{array}{l}1.14 \\
(1.11\end{array}$ \\
\hline $\begin{array}{l}\text { Basic model + } \\
\text { health behaviours }\end{array}$ & 1 & $\begin{array}{l}1.13 \\
(1.01 \\
1.27)\end{array}$ & $\begin{array}{l}1.17 \\
(1.02,\end{array}$ & $\begin{array}{l}1.26 \\
(1.06,\end{array}$ & $\begin{array}{l}1.20 \\
(0.97 \\
1.18)\end{array}$ & $\begin{array}{l}1.22 \\
(0.97,\end{array}$ & 0.01 & $\begin{array}{l}1.05 \\
(1.02,\end{array}$ \\
\hline $\begin{array}{l}\text { Basic model + } \\
\text { any mobility }\end{array}$ & 1 & $\begin{array}{l}1.18 \\
(1.05\end{array}$ & (1.22 & $\begin{array}{l}1.34 \\
(1.13,\end{array}$ & $\begin{array}{l}1.24 \\
(1.01\end{array}$ & (1.04, & 0.003 & $\begin{array}{l}1.07 \\
(1.03,\end{array}$ \\
\hline $\begin{array}{l}\text { Basic model + } \\
\text { chronic conditions }\end{array}$ & 1 & $\begin{array}{r}1.27 \\
(1.14\end{array}$ & $\begin{array}{r}1.38 \\
(1.20 \\
159)\end{array}$ & $\begin{array}{r}1.56 \\
(1.32 \\
185)\end{array}$ & $\begin{array}{c}1.42 \\
(1.16 \\
175)\end{array}$ & $\begin{array}{l}1.74 \\
(1.39 \\
2.18)\end{array}$ & $\begin{array}{l}<0.00 \\
1\end{array}$ & $\begin{array}{l}1.12 \\
(1.09 \\
116)\end{array}$ \\
\hline $\begin{array}{l}\text { Basic model }+ \\
\text { tests of cognitive }\end{array}$ & 1 & $\begin{array}{l}1.19 \\
(1.06 \\
133)\end{array}$ & $\begin{array}{l}1.25 \\
(1.09 \\
1.44)\end{array}$ & 1.39 & 1.30 & $\begin{array}{l}1.46 \\
(1.16\end{array}$ & $\begin{array}{l}<0.00 \\
1\end{array}$ & 1.09 \\
\hline $\begin{array}{l}\text { Basic model + } \\
\text { circulatory }\end{array}$ & 1 & $\begin{array}{l}1.27 \\
(1.13\end{array}$ & $\begin{array}{r}1.42 \\
(1.23\end{array}$ & $\begin{array}{c}1.55 \\
(1.31\end{array}$ & $\begin{array}{l}1.46 \\
(1.19 \\
179)\end{array}$ & $\begin{array}{r}1.67 \\
(1.33\end{array}$ & $\begin{array}{l}<0.00 \\
1\end{array}$ & $\begin{array}{l}1.12 \\
(1.09,\end{array}$ \\
\hline $\begin{array}{l}\text { Basic model + all } \\
\text { illnesses and }\end{array}$ & 1 & $\begin{array}{r}1.22 \\
(1.09\end{array}$ & $\begin{array}{l}1.37 \\
(1.19 \\
1.58)\end{array}$ & $\begin{array}{r}1.51 \\
(1.27 \\
1.78)\end{array}$ & $\begin{array}{l}1.31 \\
(1.07\end{array}$ & $\begin{array}{l}1.63 \\
(1.30\end{array}$ & $\begin{array}{l}<0.00 \\
1\end{array}$ & $\begin{array}{l}1.11 \\
(1.08,\end{array}$ \\
\hline $\begin{array}{l}\text { Fully adjusted } \\
\text { without tests of }\end{array}$ & 1 & $\begin{array}{r}1.27 \\
(1.14 \\
1.42)\end{array}$ & $\begin{array}{r}1.38 \\
(1.20 \\
159)\end{array}$ & $\begin{array}{r}1.56 \\
(1.32 \\
1.85)\end{array}$ & $\begin{array}{c}1.42 \\
(1.16 \\
175)\end{array}$ & $\begin{array}{l}1.74 \\
(1.39 \\
2.18)\end{array}$ & $\begin{array}{l}<0.00 \\
1\end{array}$ & $\begin{array}{l}0.99 \\
(0.96 \\
1 \cap 3)\end{array}$ \\
\hline Fully adjusted & 1 & $\begin{array}{c}0.97 \\
(0.86 \\
1 \cap 9)\end{array}$ & $\begin{array}{r}1.00 \\
(0.86 \\
115)\end{array}$ & $\begin{array}{l}0.96 \\
(0.81 \\
114)\end{array}$ & $\begin{array}{l}0.88 \\
(0.71 \\
1 \cap 8)\end{array}$ & $\begin{array}{l}0.87 \\
(0.69 \\
111)\end{array}$ & 0.75 & $\begin{array}{l}0.98 \\
(0.95 \\
101)\end{array}$ \\
\hline
\end{tabular}

${ }^{\mathrm{a}}$ Basic model is adjusted for age, sex and ethnicity; ${ }^{\mathrm{b}}$ Socioeconomic position comprises occupational social class according to the National Statistics Socio-economic Classification (NS-SEC) and total wealth (excluding debt and regular pension payments); ${ }^{c}$ Self-reported use of antidepressants in wave 0 comprising of: SSRI = Selective Serotonin Reuptake Inhibitors (BNF: 40303) and Tricyclic antidepressants (BNF: 40301); ${ }^{\mathrm{d}}$ Health behaviours comprise smoking status, alcohol intake (per year) and physical activity; ${ }^{\mathrm{e}}$ Tests of cognitive function were on: memory and executive function; ${ }^{\mathrm{f}}$ Chronic conditions were COPD and other chronic respiratory conditions, asthma, diabetes (types 1 and 2) and arthritis; ${ }^{\mathrm{g}}$ Circulatory disease and risk factors comprise of hypertension, previous heart attack, stroke, angina, and congenital heart conditions. 
Table 5. Hazard ratios (95\% confidence intervals) for all-cause mortality according to depressive symptoms excluding deaths in first 5 years after wave one $(n=10,122)$

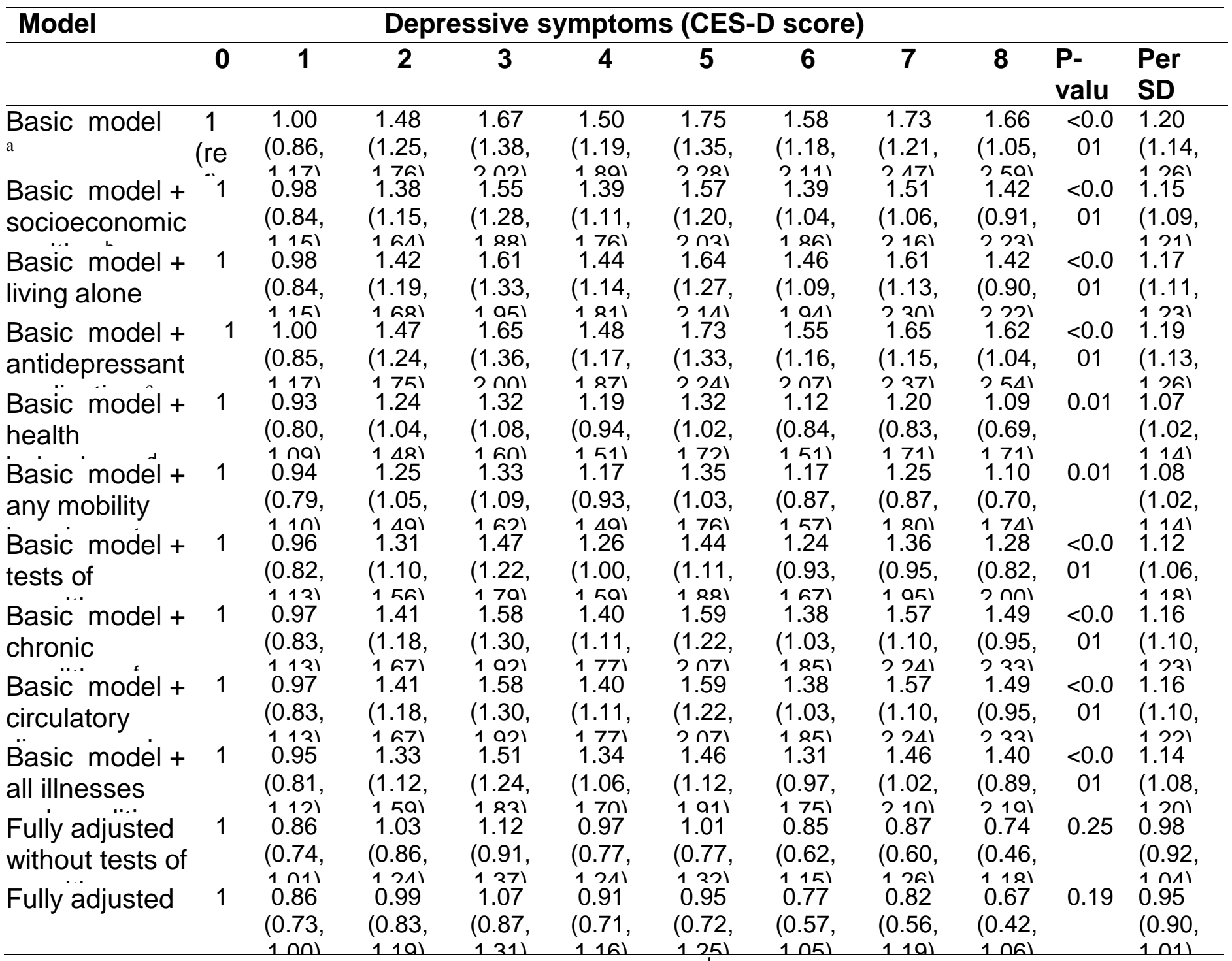

${ }^{a}$ Basic model is adjusted for age, sex and ethnicity; ${ }^{b}$ Socioeconomic position comprises occupational social class according to the National Statistics Socio-economic Classification (NS-SEC) and total wealth (excluding debt and regular pension payments); ${ }^{\mathrm{c}}$ Self-reported use of antidepressants in wave 0 comprising of: SSRI = Selective Serotonin Reuptake Inhibitors (BNF: 40303) and Tricyclic antidepressants (BNF: 40301); ${ }^{\mathrm{d}}$ Health behaviours comprise smoking status, alcohol intake (per year) and physical activity; ${ }^{\mathrm{e}}$ Tests of cognitive function were on: memory and executive function; ${ }^{\mathrm{f}}$ Chronic conditions were COPD and other chronic respiratory conditions, asthma, diabetes (types 1 and 2) and arthritis; ${ }^{\mathrm{g}}$ Circulatory disease and risk factors comprise of hypertension, previous heart attack, stroke, angina, and congenital heart conditions. 


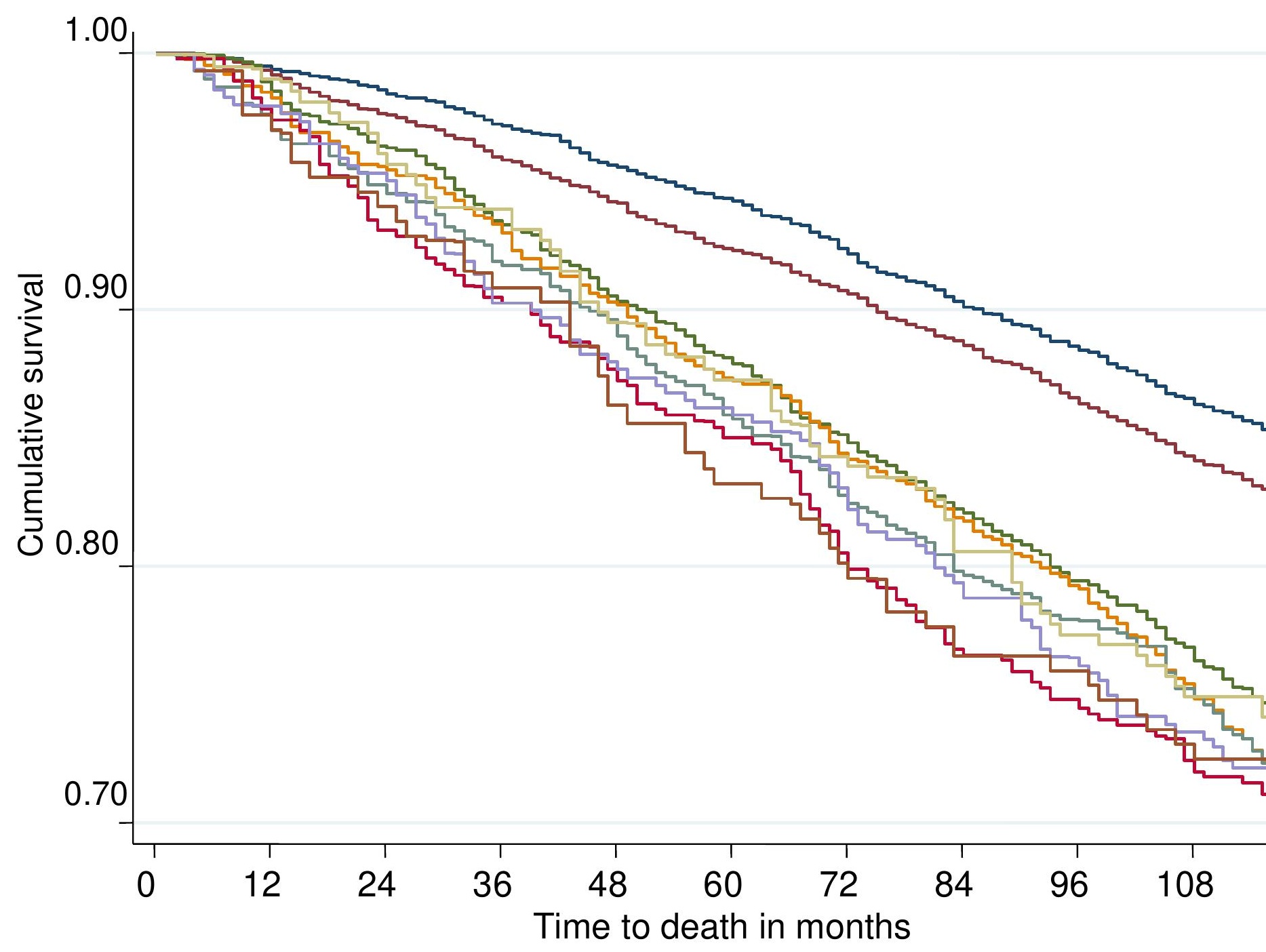

Figure S1. Kaplan-Meier survival curve for all-cause mortality according to severity of depressive symptoms (higher CES-D score indicates greater depressive symptoms). 
Items of the 8-item version of the Center of Epidemiological Studies-Depression Scale. Much of the time during the past week...

Yes $=1 ;$ No $=0$. Total score range from 0 to 8 .

... did you feel depressed?

... did you feel everything you did was an effort? *

... was your sleep restless? $*$

... were you happy?

... did you feel lonely?

... did you enjoy life?

... did you feel sad?

... were you unable to get going? *

* Items assessing somatic symptoms 